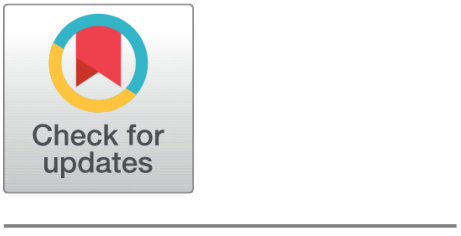

OPEN ACCESS

Received: 29-04-2020

Accepted: 12-06-2020

Published: 29-06-2020

Editor: Dr. Natarajan Gajendran

Citation: Zhang C, Liu J, Chhachhar AR (2020) A comparative study of the global internet governance system between China and the United States. Indian Journal of Science and Technology 13(23): 2303-2310. https://doi.org/ 10.17485/IJST/v13i23.774

*Corresponding author. Jian Liu

School of Communication, Yunnan Normal University, China liujianthu@qq.com

Funding: None

Competing Interests: None

Copyright: (c) 2020 Zhang, Liu, Chhachhar. This is an open access article distributed under the terms of the Creative Commons Attribution License, which permits unrestricted use, distribution, and reproduction in any medium, provided the original author and source are credited.

Published By Indian Society for Education and Environment (iSee)

\section{A comparative study of the global internet governance system between China and the United States}

\author{
Chen Zhang ${ }^{1}$, Jian Liu ${ }^{2 *}$, Abdul Razaque Chhachhar ${ }^{3}$ \\ 1 School of Fashion Communication, Beijing Institute of Fashion Technology, 100029, China \\ 2 School of Communication, Yunnan Normal University, China \\ 3 Department of Media and Communication Studies, University of Sindh, Jamshoro, Pakistan
}

\section{Abstract}

Objectives: To study on the Internet governance and effect factors of the order of cyberspace, "multi-stakeholder" governance concept and legal rules in global Internet governance. Method: Based on the literature of Internet governance theory and open source data, this study makes a critical analysis of global governance strategies in the United States and China. Findings:Since the definition of Internet governance was explicitly determined during the World Summit on the Information Society (WSIS) in 2004, the United States have proposed the "multi-stakeholder" governance concept, whereas the global Internet governance system advocated by China believes that the mode of "multilateral and democratic intergovernmental cooperation" should be promoted under the leadership of the United Nations. The paper puts forward for the first time the three most important focal points of China and the United States in the global Internet governance system, including of formulation of legal rules, the allocation of key resources, and the management of multinational institutions. This study found that the global Internet governance should carry out the transformation from IPv4 to IPv6, DNS management and other work, to prevent the root server only in the hands of individual countries. Improvement:International organizations should promote the internationalization of the Internet corporation for assigned names and Numbers (ICANN) and the Internet corporation for assigned Numbers (IANA), avoid completely excluding government agencies, and strive to promote the common cooperation of multiple global stakeholders.

Keywords: Internet governance system; legal rules; key resources; management of multinational institutions 


\section{Introduction}

Before studying the Internet governance system, it is worth exploring a widely distributed opinion in the 1990s. In 1996, John Peny Barlow published a letter addressed to national governments expressing dissatisfaction and protest about the extension of government authority to the cyberspace. Some as the declaration of independence of cyberspace regarded this letter. At that time this opinion conformed to the massive popularization of the Internet and the trend of increasing interconnectedness, however, freedom without constraints started to have negative effects. Today, even John Peny Barlow himself cannot deny that if the Internet, as a part of society, is not properly governed, potential dangers might be left.

Today, in the context of globalization and informatization, "governance" is the cornerstone of the development of the Internet. Through research on the global practices of Internet governance, it is found that the United Kingdom emphasizes governance within the legal framework; France focuses on coordinated management from the industry chain of the Internet; the European Union follows the overall principle of cooperation between governments and enterprises, advocating supervision and intervention within a certain limit. Singapore governs the Internet by adopting the principles of obedience, compromise, and competition. The United States proposes a principle that on the one hand, adopts the attitude of common prosperity and openness to treat Internet governance, and emphasizes the free flow and intercommunication of digital information as the core principle; on the other hand, underscores the importance of government standards in the ever-changing global strategic and security environment.

China expressed its concept of Internet governance during the $2^{\text {nd }}$ World Internet Conference, which encompassed four principles about the "governance system", or respect for cyber sovereignty, maintenance of peace and security, promotion of openness and cooperation, and cultivation of good order. A careful comparison shows that China and the United States have different policies and management mechanisms over the "Internet governance system" which is partly due to the influences of the social system, economic environment, and diplomatic strategies, whereas the fundamental reason is the conflict between the "open and free" principle and "network boundary and control". Generally speaking, how the global Internet governance system should be established and operated has long been the key divergence of opinion between China and the United States. To understand the different strategies proposed by the two nations, it is important to first understand what Internet governance is and its component.

\section{Concepts and Theory}

\subsection{The evolution of the concept of "Internet Governance"}

The concept of "Internet governance" on the Internet governance system evolves over time. The term "Internet Governance" used in academic research in China came from the translation of "Network Governance". The transition from "network governance" to "Internet governance" reflects deep changes in the governance environment and behavioral mechanisms. In terms of the specific interpretation, "network" refers to a broader range of meanings. In public management, the concept of "network governance" not only covers the software and hardware management of communication technology, but also refers to the coordinated governance involving both internal and external stakeholders. Overall, "network governance" emphasizes efficient, broad participation in a more reasonable structural system. In addition, "network" is a broader concept, which includes telecommunications networks, limited television networks, urban networks, transportation networks, and social networks except for computer networks ${ }^{(1)}$.

In contrast, in the information era, the term "Internet" not only accurately describes the technical characteristics of social, technological, and cultural development, but also directly conveys the characteristics of "interconnectedness and commonality". Further, analyses found that "Internet", from a technical point of view, is an information application network built upon the TCP / IP protocol system. The first time the term "Internet" was put together with "Governance" as one special term was in 2004 during the World Summit on the Information Society (WSIS) which formulated the Geneva Plan of Action explicitly expressing the need to define the concept of "Internet governance". Subsequently, it was defined in the work report of the Internet governance group as: "Internet governance is the development and application by governments, the private sector, and civil society, in their respective roles, of shared principles, norms, rules, decision-making procedures, and programs that shape the evolution and use of the Internet ${ }^{(2)}$ From this definition, governments, commercial corporate, and individual citizens can all participate in Internet governance? Some scholars have expressed different views. The U.S. Internet governance researcher Mueller believes that this definition is too narrow in a certain important aspect. Governance not only occurs in formal decision-making authorities such as the United Nations or Internet Corporation for Assigned Names and Numbers, but also involves thousands of network operators and service providers connected by Internet protocols, and sometimes even from users themselves ${ }^{(3)}$. 
This shows that "Internet governance" by integrating the implications of democratic participation and autonomous management and the concept of deauthorization, which resonates with the concept of governance, is not imposed by an overarching political authority, but by cooperation and supervision of interdependent stakeholders ${ }^{(4)}$.

The historical concept of Internet governance, regardless of whether it emphasizes government dominance or participation from civil society, can no longer properly describe the current global governance environment. The meaning of governance is not only limited to the management of node devices and transmission chains on the basis of the basic communication and computer infrastructure; or a discussion of the topics, subjects and management methods; instead, it extends to an evaluation of the global comprehensive network strengths to reach a balance of power within a certain framework of rules, so as to avoid the threat imposed by one party's excessive authority. If the reality is believed to have triggered the conceptional change, then the conceptional change also reflects the flow of power. For instance, regarding the management authority of the basic Internet resources, in March 2014, the U.S. Department of Commerce National Telecommunications and Information Administration (NTIA) announced plans to relinquish its stewardship over the Internet Assigned Numbers Authority (IANA) to the global multi-stakeholder Internet community, indicating that "Internet governance" increasingly needs to be developed in a systematic manner.

\subsection{The theoretical background of "'Internet Governance"}

Looking at the China's academic researches, the search in CNKI with the keyword "Internet governance" returned 554 papers, with 84 papers published in 2014 and 2015, a record number in history. These 84 papers cover perspectives including political economics, management, and communication and analyze the aspects of the structure, legislation, and system of Internet governance. In terms of the academic research of foreign countries, according to ${ }^{(5)}$ elaborates on the concept of the commons-based peer production based on the cooperative-production mode adopted by open-source software developers. In Coase's Penguin or Linux and The Nature of the Firm, for the first time analyzed the phenomenon of commons-based peer production. ${ }^{(5)(6)}$ put forward the idea of "networking" work from observations of open source production. Later on, several theories of Internet governance have emerged, one of which is based on the commons-based peer production concept, which was conceived by opensource software developers. Similar to the concept of network organization in some aspects, the concept of commons-based peer production describes how open-source software and its developers rely on non-bureaucratic, mostly voluntary cooperative technologies. David Johnson, Susan Crawford, and John Palfrey have all used the concept of commons-based peer production in Internet governance.

An opposing view is the "multi-stakeholderism" concept, which refers to international organizations with nations as the foundation opening to stakeholders other than governments. The multi-stakeholder model of governance means that representatives of public interest advocacy groups, business associations, and other interest groups can participate in intergovernmental policy discussions ${ }^{(6)}$. In addition, Goldin and Murdoch, well-known researchers on subjects of communication politics and economics, emphasized a democratic social atmosphere from the perspective of politics in Internet governance.

Internet governance theory has consistently embodied the concept of "systematization" aimed at filling the gap between national institutions and global connectivity, which is defined as a relatively stable connection between stakeholders that depend on each other yet have operational independence ${ }^{(7)}$ The theory of systematic governance underlines more on a cooperative relationship between governments, organizations, and individuals in global cooperation, relying on common consciousness, laws and regulations, and open platforms to achieve governance goals.

From the perspective of management, systematization means that Internet governance can perform internal combination and restructure according to a certain order, both in concept and in rules of behavior. The global Internet governance is composed of five elements - the subjects, objects, rules, values, and results of governance, and is designed to achieve common goals or resolve common problems through the formulation and implementation of global or regional rules of governance. ${ }^{(4)}$ The organic composition of these five elements cannot be separated from the core of governance. What composes the complicated core concept can be discussed from the historical practices that have formed the governance system.

From 1994 to 1998, Internet governance-related discussions were held around the topic of cooperation about the global Internet domain name and address, which eventually led to the establishment of Internet Corporation for Assigned Names and Numbers (ICANN) in 1998 as a milestone. ICANN adopts a new non-governmental model, composed of representatives from the business, academia, and industry fields. ICANN is responsible for Internet Protocol (IP) address space allocation, protocol identifier assignment, generic (gTLD) and country code (ccTLD) Top-Level Domain name system management, and root server system management functions, which were all performed under the contractual agreement with the U.S. government. Although ICANN, an institution designed to promote competition and represent the interests of global Internet organizations, was approved to separate from the intervention of the U.S. government in 2009, it has long been operating for the unilateral interest of the U.S. Another significant event of the practices of Internet governance was holding the World Summit on Infor- 
mation Society (WSIS). From 2002, multilateral and nation-centric diplomatic conferences have been held multiple times. The 2003 WSIS held in Tunis proposed to discuss around the necessity and main content of Internet governance, and urged the then Secretary General of United Nations, Kofi Annan, to form the Working Group on Internet Governance (WGIG). From the 2003 Geneva Plan of Action to the 2005 Tunis conference and the 2013 Montevideo Statement on the Future of the Internet, topics around the global Internet governance were repeatedly discussed.

The above summary of the relevant conferences and focus of discussions revealed that Internet governance has evolved from loose practices to "systematized" "global" practices. Returning to the focus of this section, that is how to retain the value of Internet stakeholders to constitute the core of the governance system. As such, the formulation of international rules, the allocation of key resources, and the management of multinational institutions are proposed here as the most crucial items, which also correspond to three questions, that is, what are the rules underlying the Internet governance system, who should formulate the rules, and who will supervise.

\section{An in-depth analysis of the global internet governance system}

After the dissolution of the Soviet Union in 1990, the U.S. adjusted the global strategies in which the transformation of the Advanced Research Projects Agency Network (ARPANET) was related to the Internet. ARPANET, a distributed network initially established for military purposes, is considered the predecessor of the Internet and its transition from a military project to a civilian one gave the U.S. an absolute advantage in the development of the Internet. For example, in 1989, Tim Berners-Lee invented the World Wide Web, which was actually connected by hyperlinks allowing users to view the content through a web browser. By 1998, there were around 130 million devices connected to the World Wide Web, half of them in the United States, and China also had millions of computers connected to the web. Previously, the Oxford Internet Institute created "The World Online" map based on Internet user data released by the World Bank in 2013. This map does not follow the same scale as the general geographic map; rather, the number of Internet users in that country determines the size of each country.

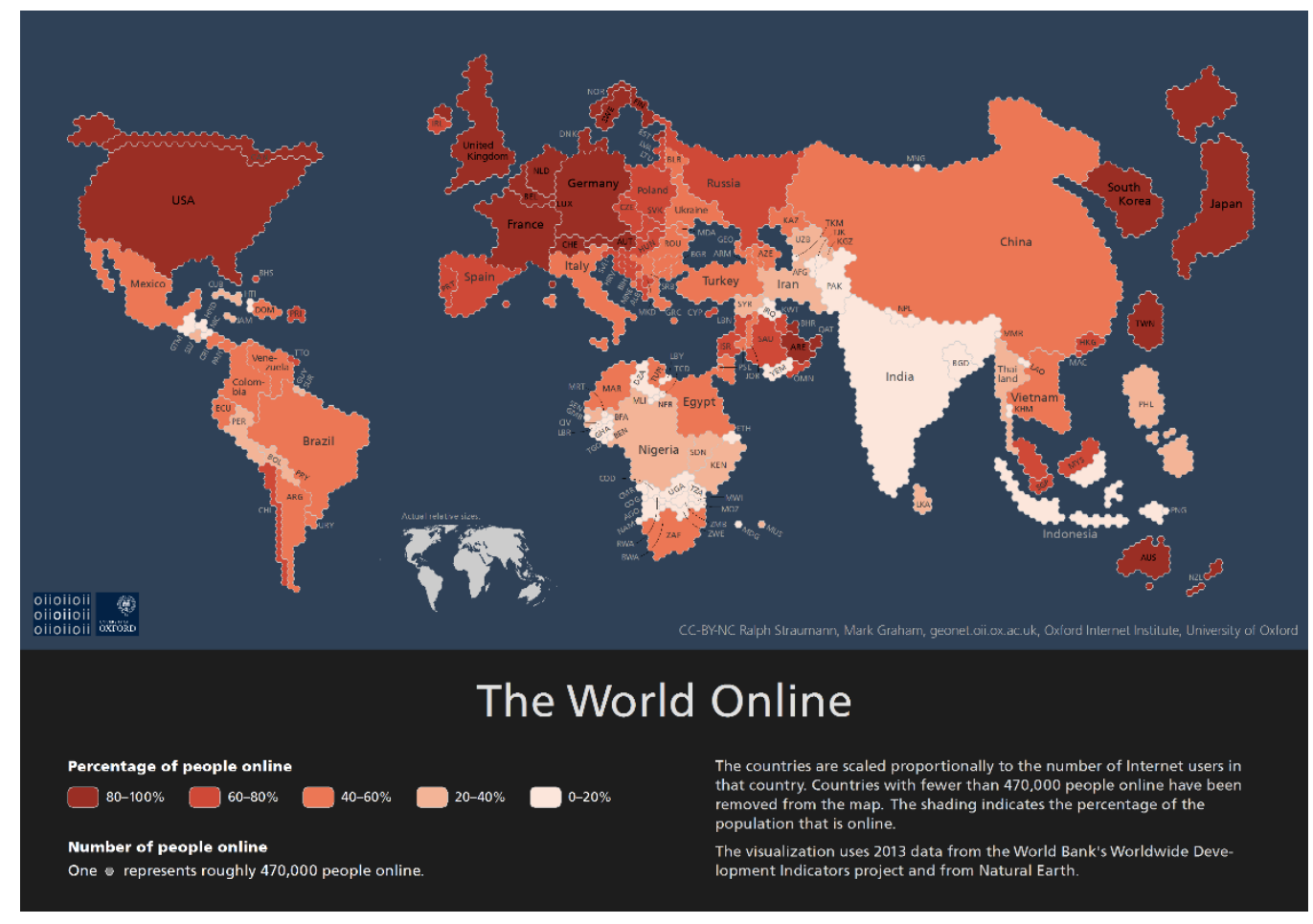

Fig 1. World Internet Users Map

According to Figure 1, China falls into the category of $60 \%-80 \%$ Internet penetration rate (the U.S. falls into the range of $80 \%-100 \%$ ), whereas the number of online users has also surpassed other countries including the United States. However, the reality is that the U.S. still holds a monopoly over Internet architecture and technical specifications. As such, the establishment of a multilateral, democratic global Internet governance system is still a complex project. The United States and China have 
three controversial issues regarding the "openness" principle of Internet governance.

\subsection{Who should formulate the international rules of the internet}

The effective operation of the Internet governance system is inseparable from the rules formulated regarding the Internet, and the extent to which international rules are adopted is related to the existing comprehensive national power of the rule-makers. To study this issue first requires a clear understanding of the existing legal system in the governance framework. In addition to the relevant laws and regulations about international network security, the importance of international treaties about the Internet cannot be underestimated. In 2001, the European Commission composed of $26 \mathrm{EU}$ members, alongside the United States, Japan, and other countries, signed the Convention on Cybercrime which includes four chapters, "Preamble", "Use of terms", "Measures to be taken at the national level", "International co-operation", and "Final provisions". At the core of the Convention is Chapter II "Measures to be taken at the national level", which consists of three sections: "Substantive criminal law", "Procedural law", and "Jurisdiction ${ }^{(8)}$. As the first international convention formulated for attacking cybercrime, it directly promotes international cooperation to combat cybercrime and also has a positive impact on the enaction of the criminal law for cybercrime in China. No matter it is the formulation of laws and regulations, or signing international treaties, the purpose is to reduce conflicts in legal sentencing to better protect cyber sovereignty.

The transborder nature of the Internet means that many of the old legal rules need to be changed. However, how the Internet should keep operating within the current legal framework remains a focus of debate. Ten years after the signing of the Convention on Cybercrime, the Global Conference on Cyberspace was held in London in 2011, where 700 representatives from 60 countries stated three categories of ideas regarding the existing rule system, which were put forward in conformity to their respective interests. Some countries believed that given the global Internet technology and the environment had experienced tremendous changes, making adjustments to the existing rules within the legal framework of the Charter of the United Nations and the international law can prevent too hasty and drastic changes while also maintaining their advantages in the rule-making process; some countries directly expressed the desire for redefining the network governance rules. The Convention on Cybercrime mentioned above, for instance, was enacted in 2001 and after 15 years, many of the technologies and means of crime have become completely different, especially in terms of how to cooperate with different countries. Modifications and improvement may not be able to effectively combat cybercrime and therefore, reformulating relevant rules has become an urgent item on the agenda. There is another small portion of countries that expressed positions to keep the existing international laws and rules unchanged and strengthen the level of law enforcement and supervision. The three types of arguments reflected rule-makers' competition for power, which originated from some of the main countries' consideration of their respective interests outside the consultation system. For example, although the United States signed the Convention on Cybercrime, the White House still issued the National Cyber Strategy in 2011 as the formal jurisdiction of the Convention on Cybercrime falls within the interest framework of the European Union; The United Kingdom convened the $23^{\text {rd }}$ G8 Summit in Deauville, proposing discussions around topics favorable to its own interests such as personal information protection and combat against cybercrime; the International Code of Conduct for Information Security advocated by China and Russia proposed to establish a new international organization within the United Nation framework to formulate rules regarding cyberspace. A revised draft submitted at the $69^{\text {th }}$ Session of the United Nation in January 2015, which primarily proposed to form relevant international guidelines as soon as possible to regulation online information and activity.

Even though each country has its own set of propositions in the formulation of international rules, an international rule accepted by most countries is still needed to maintain the world order. Regarding this, China has sped up efforts to facilitate the global legislation process on multiple platforms such as the World Summit on the Information Society (WSIS) and the Global Internet Forum (GIF); the United States has passed the National Cyber Strategy which puts forward the core concept and principles of cyberspace, and in 2014 transferred its historic stewardship over the Internet Assigned Numbers Authority. But it is worth noting that the global Internet governance alliance sponsored by China has no management mechanism to cooperate with the United States. In the transfer of stewardship over ICANN, the United States still integrates the NTIA standards to extend its dominant power in network governance.

In short, in the cyberspace governance system, there have been heated debate and trade-offs between the "Internet Principles of Freedom" proposed by the United States and the "Internet Sovereignty" principles proposed by China, and eventually, a widely recognized legal norm was established. The implementation and supervision of the rules require the role of a non-conventional multinational institution that shall involve multinational corporations, non-governmental organizations, government agencies, and individuals. The content of this aspect will be analyzed in detail later. 


\subsection{How to allocate key resources of the internet}

The dispute over the supervision of key resources of the Internet has long been the focus of governance. Since the 1980s, the United States has been facilitating the protection of resource management through the issuance of the presidential decree and government announcements. In May 1998, the Critical Infrastructure Protection (PDD 63) decree was issued which for the first time clarified the significance of key resources management to information security, signaling that the importance of key resources protection has been elevated to the national level. Influenced by the changing global political and economic environment and the September 11 attacks, Executive Order 13231, "Critical Infrastructure Protection in the Information Age" was issued in 2001 which upgraded the Critical Infrastructure Assurance Office to the President's Critical Infrastructure Protection Board composed of the Secretary of State, the Secretary of Defense, the Minister of Justice, the Minister of Commerce, the Director of the Office of Management and Budget, the Chairman of the National Economic Council, and the Assistant to the President for National Security Affairs, indicating that the management of key resources involves various governmental organs. Different from the domestic Internet governance system, the United States strongly opposes introducing the role of governments into the ICANN when it comes to global Internet governance. In contrast, China advocates that the role of governments is indispensable for the facilitation of Internet governance, especially for developing countries, which lack behind in terms of infrastructure development. However, who should take charge has become the focus of debate, which involves the issue of global Internet resource control and can be specifically divided into two categories: IP address allocation and the DNS management system.

\subsubsection{Issues of the fairness and ownership of IP addresses}

The IP address refers to the Internet address assigned to each device connected to the network and is unique. The encoding of the IP address is referred to as the Internet Protocol. In 1970s, Vint Cerf invented an IPv4 address, which has a size of 32 bits limiting the address space to about 4.3 billion addresses. In the early stage of Internet development, the domain name and nature of the entire IP addresses were managed by just one person, however, as the number of Internet users increased, more professional management over IP addresses have emerged which gradually replaced the conventional random management, which also triggered two major issues of fairness and ownership of IP address allocation. In the early days of Internet development, U.S. universities and companies occupied a large number of IP addresses. Zhao Houlin, deputy secretary general of the International Telecommunication Union (ITU), once said that the United States has a population of only 300 million but has close to $40 \%$ of the global IP addresses. By 2014, China had nearly 331 million IP addresses, ranking second in the world; however, the number was still only one-fifth of that in the United States.

The existing IP address management principle put the entire developing world in an unfavorable situation. In May 2015, ICANN, which is in charge of allocation of IP addresses, publicly announced that IP addresses are about to be exhausted, which indicated that countries at a disadvantaged position will pay high costs in the future. The tightened IP address allocation policy has triggered a transition to IPv6, whose progress, however, has been rather slow since its origin in 1995. First of all, it does not show significant advantages and has no direct effects on the speed of Internet access. Secondly, the transition from IPv4 to IPv6 is a major project, which would require all the end users to replace their router or modem that connects the terminal to the Internet. All the websites and website operators must also be fully transformed to provide a suitable access point for IPv6. The current situation in China is that telecommunications operators have not approved applications, and thus, IPv6 addresses have not been allocated in large quantities. The high application and processing fee has also hindered the promotion of IPv6. Despite the slow deployment of IPv6, China has initiated the China Next Generation Internet Project (CNGI), the largest pilot project of this type in the world as early as 2003. The CNGI network includes six IPv6 backbone networks (covering 22 cities nationwide and connecting 59 core nodes), 2 domestic / international exchange centers and 273 resident networks. In 2008, the United States suddenly increased its application for IPv6 addresses and subsequently obtained the most IPv6 addresses in the world.

At present, ICANN, as the global Internet IP address and domain name allocation and management agency, is still indirectly affiliated with U.S. Department of Commerce and the National Telecommunications and Information Administration, and even indicated in the IANA stewardship transfer plan that the authoritative root zone files accord with the NTIA standards. In the future, on the issue of how to allocate IP addresses for the next-generation Internet, the International Telecommunication Union, as a United Nations agency, advocates that ITU shall directly allocate IP addresses to countries for free. Although this is expected to break ICANN's monopoly, ownership of IP addresses still remains a key issue in the debate over IP address development. 


\subsubsection{Issues of DNS management systems}

The fundamental function of DNS is to achieve the dynamic mapping between host domain names and IP addresses. Currently, among the multi-level servers that can provide "DNS resolution" in the world, the only authoritative root name server is located in Virginia of the U.S. The root name servers are the servers that assume the function of the root node in the domain name system. It enables the authoritative name server of the root domain to master all the authorization details of international toplevel domains. Of the 13 root name servers across the world, 10 are located in the United States, the other three in the United Kingdom, Sweden, and Japan, all of which are managed by ICANN. In addition, more than 120 mirror name servers have been deployed globally.

Currently, China cannot set up a root name server, having only the right to lease and use the Internet instead of the right to administer. Therefore, the next step is to compete for the root name server. Till today, the United States, Australia, and New Zealand have written cyber warfare into their national defense act. In other words, once conflict occurs in the cyberspace, the above countries would directly enter a state of war. Specifically, once a country in control of the root name server leads cyber warfare, it can directly expel the countries without root name servers from the global Internet market.

\subsection{Who should supervise multinational institutions}

The composition and authority of multinational institutions are the embodiment of who controls more power in terms of Internet governance. Research showed that China advocates various forms of cooperation at the government level, which include cooperation with not only other governments but also multinational corporate and non-governmental organizations. This method is also suitable for other developing countries or less developed countries that seek to take advantage of the evolving Internet to enhance their positions on the Internet world. China has demonstrated a series of relatively clear plans regarding the global Internet governance system. As early as 2003, in the first phase of the World Summit on the Information Society (WSIS) in Geneva between November and December, representatives of China expressed the proposition that national governments should participate in the management of the Internet, which is a kind of public resource, reflecting the "government-led, multiparty participation" position. The Declaration of Principles passed in Geneva at that time explicitly stated that "the international management of the Internet should be multilateral, transparent and democratic, with the full involvement of governments, the private sector, civil society, and international organizations." Such multilateral governance principle has a drastically opposite relationship with the "unilateral system" of the U.S. implemented by the Internet Corporation for Assigned Names and Numbers.

The relationship between the United States and the Internet Corporation for Assigned Names and Numbers (ICANN) is a contractual relationship. Although ICANN has the authority to allocate IP address resources, modify root zone files, and coordinate the allocation of unique protocol identifiers, changes made to the root zone files managed by the Internet Assigned Numbers Authority must be reviewed and approved by the U.S. Department of Commerce. Besides, the U.S. Department of Commerce and the Internet Corporation for Assigned Names and Numbers (ICANN) have reached a memorandum of understanding, implying that this so-called private institution is actually controlled by a national government which has unrestricted authority; at the same time, the ICANN also has the power to formulate policies and its committee also consists of "multi-stakeholders" advocated by the United States which include participants from the government, business sector, and civil society. How to avoid the issue that the "multi-stakeholder" is merely a formality and realize multi-stakeholder management and decision-making? No clear plan has been formed to resolve this issue. A careful analysis of ICANN also revealed that $75 \%$ of their internal staff is from North America, 15\% from Europe and only 10\% from Asia, Africa and Latin America, which is hard to ensure a balance of interests in Internet governance.

\section{Conclusion}

After comparing the different Internet governance systems advocated by China and the United States, it is found that the focus of Internet governance is to ensure cyber security and conduct supervision over the Internet within the legal framework; to transition from IPv4 to IPv6 and conduct administration over DNS, and change the situation that root name servers are only controlled by a few countries; to promote the globalization of the Internet Corporation for Assigned Names and Numbers (ICANN) and the Internet Assigned Numbers Authority (IANA), and avoid the complete elimination of government agencies from the governance system to promote worldwide cooperation of multiple stakeholders. When looking back on the history of the Internet, it is apparent to find that U.S. corporations have controlled core network technologies, important multinational institutions were registered in the United States, and the U.S. corporations and U.S. government dominate the global Internet governance system. However, it is widely known that the operation and governance of the Internet require the existence of order, and order originates from two points: consensus and balance. The balance of power, in particular, has become the driving force 
of the formation of the governance order. No single country will not be affected by the global Internet governance system, especially China. In the third decade after formally connected to the global Internet, it is an inevitable choice for China to combine domestic governance with global governance of the Internet and strengthen cooperation with other international communities.

\section{Acknowledgment}

This work was financially supported by the National Social Science Found of China (Grand No. 18CXW032).

\section{References}

1) Xiaoying $Z$ and Weishan M . 2015,.

2) Bossey CD. Report of the working group on Internet governance . 2005,. Available from: http://www.wgig.org/docs/WGIGREPORT.pdf.(lastvisit.

3) Mueller ML. Networks and states: The global politics of Internet governance. Shanghai Jiao Tong University Press . 2015,. p. 11-12. Available from: https://books.google.com.pk/books?hl=en\&lr=\&id=qH3TAvkAtsEC\&oi=fnd\&pg=PP1\&dq=Milton+L.+Mueller. + (Zhou+Cheng, + etc. + Trans. )+Networks+and+States.

4) James NR, Czempiel EO and Smith S, editors. Governance without government: order and change in world politics. vol. 20. Cambridge University Press . 1992,. Available from: https://scholar.google.com/scholar?hl=en\&as_sdt=0\%2C5\&q=Rosenau\%2C+J.+\%2C+and+O.+Czempiel\%2C+eds.+1992. +Governance+without+government\%3A+Order+and+change+in+world+politics.+Cambridge\&btnG.

5) Benkler Y. The wealth of networks: How social production transforms markets and freedom. and others, editor. Yale University Press . 2006,. Available from: https://scholar.google.com/scholar?hl=en\&as_sdt=0\%2C5\&q=Benkler\%2CT.+The+wealth+of+networks\%3A+How+social+ production+transforms+markets+and+freedom. $+\mathrm{New}+$ Haven $\% 2 \mathrm{C}+\mathrm{CT} \% 3 \mathrm{~A}+$ Yale+University+Press.\&btnG $=$.

6) Tennant R, Haseman J and Stoll RE. Transgenic assays and the identification of carcinogens. vol. 37. Wiley . 2001,. p. 86-88. Available from: https: //dx.doi.org/10.1002/1098-2280(2001)37:1<86::aid-em1010>3.0.co;2-g.

7) Sørensen E and Torfing J. Theoretical approaches to metagovernance. In: In Theories of democratic network governance. London. Palgrave Macmillan . 2007,. p. 169-182.

8) Yu Z. The Era of 'Informatization Trans-national Crime' and China's Choice regarding the Convention on Cybercrime . 2013,. 